Die Sinfonien Carl Philipp Emanuel Bachs 
Günther Wagner

\section{Die Sinfonien}

\section{Carl Philipp Emanuel Bachs}

Werdende Gattung und Originalgenie

Verlag J. B. Metzler

Stuttgart - Weimar 
Die Deutsche Bibliothek - CIP-Einheitsaufnahme

Wagner, Günther:

Die Sinfonien Carl Philipp Emanuel Bachs : werdende Gattung

und Originalgenie / Günther Wagner. - Stuttgart ; Weimar : Metzler, 1994

ISBN 978-3-476-01268-5

ISBN 978-3-476-01268-5

ISBN 978-3-476-03570-7 (eBook)

DOI 10.1007/978-3-476-03570-7

Dieses Werk einschließlich aller seiner Teile ist urheberrechtlich geschützt. Jede Verwertung außerhalb der engen Grenzen des Urheberrechtsgesetzes ist ohne Zustimmung des Verlages unzulässig und strafbar. Das gilt insbesondere für Vervielfältigungen, Übersetzungen, Mikroverfilmungen und die Einspeicherung und Verarbeitung in elektronischen Systemen.

C 1994 Springer-Verlag GmbH Deutschland

Ursprünglich erschienen bei J. B. Metzlersche Verlagsbuchhandlung und Carl Ernst Poeschel Verlag GmbH in Stuttgart 1994 


\section{INHALT}

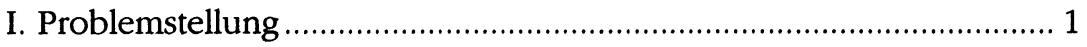

1. Anmerkungen zum Thema .............................................. 1

2. Bachs eigene Einschätzung und das Urteil der Zeitgenossen ....... 12

3. Historische Bewertung ...................................................... 22

II. Die Sinfonie in der zeitgenössischen Musiktheorie ............................ 68

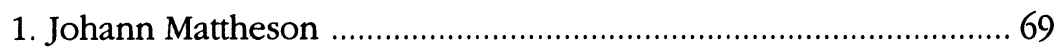

2. Johann Adolph Scheibe .......................................................... 78

3. Joseph Riepel .............................................................................. 107

4. Heinrich Christoph Koch ........................................................ 125

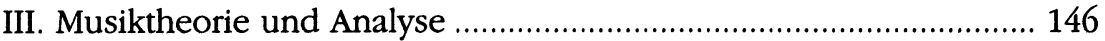

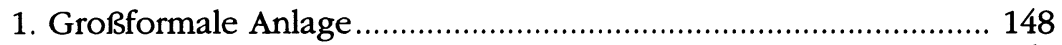

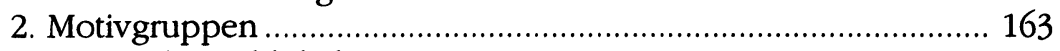

3. Nationale und lokale Komponenten .......................................... 179

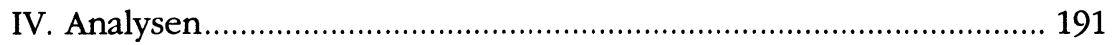

1. Großformaler Aspekt................................................................. 191

2. Motivgruppen: Struktur, Verknüpfung und Abfolge ................... 207

Exkurs 1: Johann Gottlieb Graun ................................................... 244

3. Stimmen und Satz ............................................................. 262

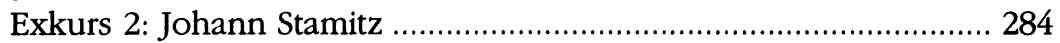

4. Motivische Arbeit................................................................ 308

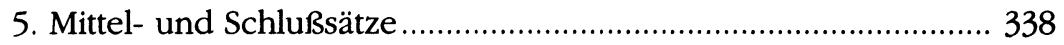

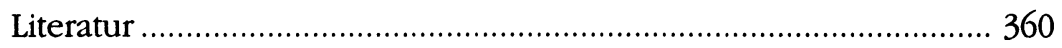

1. Quellen und ältere Literatur (bis 1850) ....................................... 360

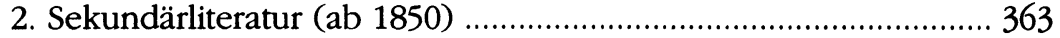

